\title{
EDITORIAL
}

\section{The World Trade Center disaster: a tragic source of medical advancement}

\author{
Vinicius C. Antao
}

$\mathbf{T}$ he history of medicine is full of examples of the determination of scientists when faced with public health disasters. As a result of this strength, many tragedies that occurred in the 20th century were followed by important scientific developments. If World War I marked the advent of chemical weapons, it also provided respiratory specialists with knowledge about the effects of poisonous gases on the lungs and led to the development of the first practical gas mask for mass production. The increased use of aircraft in warfare during World War II prompted Forrest M. Bird to develop oxygen masks to enable pilots to fly at higher altitudes than ever before. Further improvements of this technology led to the invention of the first modern ventilators, such as the Bird Universal Medical Respirator. The legacy of the Vietnam War to the medical field was the identification of acute respiratory distress syndrome (called Da Nang Lung at that time), by Colorado researchers in 1967 [1]. Other tragedies, such as the 1986 catastrophic nuclear accident of Chernobyl, led to a better understanding of the physiology of radiation poisoning, which had been evolving since the Hiroshima bombing, and helped improve treatment for victims of other disasters. There were advances in the creation of sterile hospital rooms, infection prevention, intravenous transfusion, life support systems, plasmapheresis, platelet transfusion, and bone marrow transplants.

The dawn of the 21st century saw another tragedy that will remain in the memory of many generations to come: the terrorist attacks on September 11, 2001 in New York City, NY, USA that led to the destruction of the World Trade Center (WTC) Twin Towers and other buildings, and claimed thousands of lives. In the past 10 years, hundreds of manuscripts have been published on the effects of the $9 / 11$ disaster. These papers reported on the findings of several medical monitoring programmes [2-4] as well as the largest postdisaster public health registry in US history [5]; they described new syndromes [6] and striking cases of lung injury [7]; demonstrated the association between lung and mental health problems among rescue/recovery workers [8]; and expanded the understanding of the importance of respiratory protection in disaster situations [9]. In this issue of the European Respiratory Journal, a manuscript by WEIDEN et al. [10] goes

Division of Toxicology and Human Health Sciences, Agency for Toxic Substances and Disease Registry, Atlanta, GA, USA.

CORRESPONDENCE: V.C. Antao, Agency for Toxic Substances and Disease Registry, 4770 Buford Highway NE, MS F-57, Atlanta, GA 30341, USA. E-mail: VAnta0@cdc.gov beyond traditional WTC research. It looks at the association between serum levels of cardiovascular biomarkers and subsequent development of pulmonary disease, providing new insights into the pathophysiological mechanisms of particle-induced lung injury in humans.

This area of research is developing quickly, and the hypotheses that trigger most studies are supported by two pillars: that exposure to particulates causes systemic inflammation, and that systemic inflammation is associated with both cardiovascular and pulmonary diseases.

Over the past two decades, insurmountable epidemiological evidence has been produced to reinforce that exposure to particulate matter is associated with cardiovascular disease, including elevated morbidity and mortality [11]. More recently, the mechanisms by which this interaction occurs have started to be clarified, pointing at systemic inflammation as one of the main culprits, especially among patients with metabolic syndrome [12].

The WTC dust has been characterised as a mixture of many noxious substances, including: cement dust, glass fibres, asbestos, lead, polycyclic aromatic hydrocarbons, polychlorinated biphenyls, organochlorine pesticides, and polychlorinated furans and dioxins. In addition, a toxic plume containing metals, soot, volatile organic compounds and hydrochloric acid remained in the atmosphere for several days $[13,14]$. Many of these substances have been implicated in one or more pathways of vascular inflammation in experimental models, corroborating the hypothesis that irritant exposures may damage pulmonary vessels [15-17]. Compared to Lower Manhattan residents, passers-by and building occupants, the firefighters in this study were probably the ones subject to the highest exposures to these contaminants, from many hours of working in the pile of debris at ground zero.

One of the strengths of the study by WeIDEN et al. [10] is that it relies on a well characterised cohort of firefighters, which goes through periodical medical screening, including pulmonary function tests that were available prior to the WTC disaster. Few investigators who have studied workers involved in the rescue and recovery activities of the WTC aftermath had the luxury of having pre-disaster assessments for longitudinal comparison with post 9/11 findings; let alone those who studied the general population exposed to WTC dust. Most researchers have relied on more subjective parameters, such as: comparing subpopulations with different degrees of exposure 
in relation to proximity to ground zero [18]; using control populations away from Lower Manhattan [19, 20]; and comparing their findings to national statistics [21].

Another highlight of this study is the availability of serum, which was collected and stored immediately after the event. Without such forethought, the current study would not have been accomplished. Such practice sets a standard for future events of this nature. Taking advantage of the stored serum, and in a quest to identify biomarkers that could be used to better understand and perhaps even predict risk for respiratory disease, M.D. WEIDEN and his collaborators have recently published another study from the same cohort of firefighters. Among almost 40 different biomarkers, granulocyte-macrophage colony-stimulating factor and macrophage-derived chemokine correlated better with WTC-associated airflow obstruction [22]. In this study, however, the authors focused on biomarkers that are more specific to cardiovascular disease, building on the notion that pulmonary vascular disease may occur early in the development of chronic obstructive pulmonary disease (COPD). Other investigators have also demonstrated the role of these markers. HigASHIMOTO et al. [23] showed that several biomarkers of inflammation, including C-reactive protein, were associated with lung function decline in COPD patients. In a large population-based study, SIN and MAN [24] demonstrated that Creactive protein levels were elevated in COPD patients with moderate and severe airflow obstruction, and also associated with increased risk of cardiac injury.

Nevertheless, one shortcoming of this research is the lack of objective exposure measurements. Instead, the authors used time of arrival at ground zero as a surrogate of exposure intensity [10]. This strategy has been used by other investigators and has been shown to correlate well with health outcomes [25]. However, more elaborate semiquantitative exposure assessment methods have also been devised, which could have provided a more accurate picture of exposures [26]. Ideally, a dose-response curve could have been fit to better assess the impact of exposures on cardiovascular disease biomarkers. However, it is understandable that, given the chaotic circumstances, no personal exposure measurements were obtained. In addition, this study would benefit from the inclusion of a control group not subject to WTC exposures. This way, scientists would be able to more clearly understand the impact of such exposures on a similar group of workers.

This paper goes full circle, nicely putting together exposure, inflammation, and lung function decline. The implications of these findings are significant, suggesting avenues of investigation into new methods to identify those at particular risk for particle-induced lung injury and/or COPD, and to develop novel approaches to treatment of these conditions. The scientific community once more pays tribute to all those who were injured or lost their lives in this modern tragedy. Although nothing can make up for all the suffering, perhaps lessons from their terrible experiences can still save lives in the future.

\section{STATEMENT OF INTEREST}

None declared.

\section{ACKNOWLEDGEMENTS}

The findings and conclusions in this report are those of the author and do not necessarily represent the views of the Agency for Toxic Substances and Disease Registry.

\section{REFERENCES}

1 Ashbaugh DG, Bigelow DB, Petty TL, et al. Acute respiratory distress in adults. Lancet 1967; 2: 319-323.

2 Herbert R, Moline J, Skloot G, et al. The World Trade Center disaster and the health of workers: five-year assessment of a unique medical screening program. Environ Health Perspect 2006; 114: $1853-1858$.

3 Mauer MP, Cummings KR, Carlson GA. Health effects in New York State personnel who responded to the World Trade Center disaster. J Occup Environ Med 2007; 49: 1197-1205.

4 Tapp LC, Baron S, Bernard B, et al. Physical and mental health symptoms among NYC transit workers seven and one-half months after the WTC attacks. Am J Ind Med 2005; 47: 475-483.

5 Farfel M, DiGrande L, Brackbill R. et al. An overview of 9/11 experiences and respiratory and mental health conditions among World Trade Center Health Registry enrollees. J Urban Health 2008; 85: 880-909.

6 Prezant DJ, Weiden M, Banauch GI, et al. Cough and bronchial responsiveness in firefighters at the World Trade Center site. N Engl J Med 2002; 347: 806-815.

7 Rom WN, Weiden M, Garcia R, et al. Acute eosinophilic pneumonia in a New York City firefighter exposed to World Trade Center dust. Am J Respir Crit Care Med 2002; 166: 797-800.

8 Brackbill RM, Hadler JL, DiGrande L, et al. Asthma and posttraumatic stress symptoms 5 to 6 years following exposure to the World Trade Center terrorist attack. JAMA 2009; 302: 502-516.

9 Antao VC, Pallos LL, Shim YK, et al. Respiratory protective equipment, mask use, and respiratory outcomes among World Trade Center rescue and recovery workers. Am J Ind Med 2011; 54: 897-905.

10 Weiden MD, Naveed B, Kwon S, et al. Cardiovascular biomarkers predict susceptibility to lung injury in World Trade Center dustexposed firefighters. Eur Respir J 2013; 41: 1023-1030.

11 Pope CA III, Dockery DW. Health effects of fine particulate air pollution: lines that connect. J Air Waste Manag Assoc 2006; 56: 709-742.

12 Chen JC, Schwartz J. Metabolic syndrome and inflammatory responses to long-term particulate air pollutants. Environ Health Perspect 2008; 116: 612-617.

13 Landrigan PJ, Lioy PJ, Thurston G, et al. Health and environmental consequences of the World Trade Center disaster. Environ Health Perspect 2004; 112: 731-739.

14 Lioy PJ, Weisel CP, Millette JR, et al. Characterization of the dust/ smoke aerosol that settled east of the World Trade Center (WTC) in lower Manhattan after the collapse of the WTC 11 September 2001. Environ Health Perspect 2002; 110: 703-714.

15 Campen MJ, Babu NS, Helms GA, et al. Nonparticulate components of diesel exhaust promote constriction in coronary arteries from ApoE-/- mice. Toxicol Sci 2005; 88: 95-102.

16 Chuang HC, Fan CW, Chen KY, et al. Vasoactive alteration and inflammation induced by polycyclic aromatic hydrocarbons and trace metals of vehicle exhaust particles. Toxicol Lett 2012; 214: 131-136.

17 Felty Q, Yoo C, Kennedy A. Gene expression profile of endothelial cells exposed to estrogenic environmental compounds: implications to pulmonary vascular lesions. Life Sci 2010; 86: 919-927.

18 Wolff MS, Teitelbaum SL, Lioy PJ, et al. Exposures among pregnant women near the World Trade Center site on 11 September 2001. Environ Health Perspect 2005; 113: 739-748.

19 Lin S, Reibman J, Bowers JA, et al. Upper respiratory symptoms and other health effects among residents living near the World Trade Center site after September 11, 2001. Am J Epidemiol 2005; 162: 499-507. 
20 Lin S, Gomez MI, Gensburg L, et al. Respiratory and cardiovascular hospitalizations after the World Trade Center disaster. Arch Environ Occup Health 2010; 65: 12-20.

21 Rom WN, Reibman J, Rogers L, et al. Emerging exposures and respiratory health: World Trade Center dust. Proc Am Thorac Soc 2010; 7: 142-145.

22 Nolan A, Naveed B, Comfort AL, et al. Inflammatory biomarkers predict airflow obstruction after exposure to World Trade Center dust. Chest 2012; 142: 412-418.

23 Higashimoto $\mathrm{Y}$, Iwata $\mathrm{T}$, Okada $\mathrm{M}$, et al. Serum biomarkers as predictors of lung function decline in chronic obstructive pulmonary disease. Respir Med 2009; 103: 1231-1238.
24 Sin DD, Man SF. Why are patients with chronic obstructive pulmonary disease at increased risk of cardiovascular diseases? The potential role of systemic inflammation in chronic obstructive pulmonary disease. Circulation 2003; 107: 1514-1519.

25 Banauch GI, Hall C, Weiden M, et al. Pulmonary function after exposure to the World Trade Center collapse in the New York City Fire Department. Am J Respir Crit Care Med 2006; 174 312-319.

26 Herdt-Losavio ML, Mauer MP, Carlson GA. Development of an exposure assessment method for epidemiological studies of New York State personnel who responded to the World Trade Center disaster. Ann Occup Hyg 2008; 52: 83-93. 